\title{
The role of nasal trigeminal nerves expressing TRP channels in modulation of cough threshold and urge to cough - possible clinical application
}

\author{
Jana Plevkova ${ }^{*}$, Zuzana Biringerova², Silvia Gavliakova² ${ }^{2}$ Eva Hanuskova², Tomas Buday ${ }^{2}$, Mariana Brozmanova ${ }^{2}$ \\ From 9th Symposium of Experimental Rhinology and Immunology of the Nose (SERIN 2013) \\ Leuven, Belgium. 21-23 March 2013
}

Cough is a phenomenon frequently associated with upper airway diseases and as a reflex is modulated by many afferent inputs either from respiratory tussigenic areas, but also by afferent drive from other organs. Modulation of cough by nasal afferent inputs could either facilitate cough response or inhibit it in animal models, depending on the type of trigeminal afferents which are stimulated. In recent study we focused on afferents expressing TRPA1, TRPM8 \& TRPV3 channels - channels known as relevant for airway irritants (TRPA1), menthol and other cooling substances (TRPM8) and thymol (TRPV3). Particularly menthol and thymol are substances which are frequently used in over-the-counter medication for cough and common cold based on empirical approach. Objective evidence regarding the modulation of cough in humans has never been reported. 60 human healthy volunteers participated in the study, and they have been challenged by intranasal drops containing agonists of selected ion channels: isocyanate (AITC) \& cinnamaldehyde for TRPA1, (-) menthol and (+) menthol for TRPM8 and thymol for TRPV3 ion channels in randomized order (all 10-3 M). Nasal symptom score, cough threshold $(\mathrm{C} 2)$, urge to cough $(\mathrm{Cu})$ and cumulative cough response had been assessed using capsaicin cough challenge tests. Nasal challenges of TRPA1 relevant agonists induced considerable nasal symptoms, significantly enhanced urge to cough $(\mathrm{p}<0.05)$ but modulation of $\mathrm{C} 2$ and cumulative cough response did not reach significance level. Both TRPM8 agonists and TRPV3 agonist thymol administered to the nose significantly modulated all parameters including $\mathrm{C} 2(\mathrm{p}<0.05), \mathrm{Cu}(\mathrm{p}<0.01)$ and cumulative cough response $(\mathrm{p}<0.01)$ documenting

'Comenius University, Jessenius Faculty of Medicine, Martin, Slovakia Full list of author information is available at the end of the article strong anti irritating and antitussive potential of menthol isomers and thyme. Nasal afferent drive modulates cough reflex in human healthy volunteers and this knowledge could have clinical application involved in relieving lower airway symptoms in subjects with upper airway diseases. The role of trigeminal afferents, olfactory nerve endings, smell perception process and other supramedullar influences have to be taken into consideration as relevant enough to modulate cough response in humans.

\section{Author details}

${ }^{1}$ Comenius University, Jessenius Faculty of Medicine, Martin, Slovakia. ${ }^{2}$ Comenius University, Jessenius Faculty of Medicine, Department of Pathophysiology, Martin, Slovakia.

Published: 16 July 2013

doi:10.1186/2045-7022-3-S2-017

Cite this article as: Plevkova et al:: The role of nasal trigeminal nerves expressing TRP channels in modulation of cough threshold and urge to cough - possible clinical application. Clinical and Translational Allergy 2013 3(Suppl 2):017.

Submit your next manuscript to BioMed Central and take full advantage of:

- Convenient online submission

- Thorough peer review

- No space constraints or color figure charges

- Immediate publication on acceptance

- Inclusion in PubMed, CAS, Scopus and Google Scholar

- Research which is freely available for redistribution 